\title{
Complications of epilepsy surgery in Sweden 1996-2010: a prospective, population-based study
}

\author{
Johan Bjellvi, MD, ${ }^{1}$ Roland Flink, MD, PhD, ${ }^{2}$ Bertil Rydenhag, MD, PhD, ${ }^{1}$ \\ and Kristina Malmgren, $\mathrm{MD}, \mathrm{PhD}^{1}$ \\ ${ }^{1}$ Epilepsy Research Group, Institute of Neuroscience and Physiology, The Sahlgrenska Academy, University of Gothenburg, \\ Sweden; and ${ }^{2}$ Department of Clinical Neurophysiology, Uppsala University Hospital, Uppsala, Sweden
}

\begin{abstract}
OBJECT Detailed risk information is essential for presurgical patient counseling and surgical quality assessments in epilepsy surgery. This study was conducted to investigate major and minor complications related to epilepsy surgery in a large, prospective series.

METHODS The Swedish National Epilepsy Surgery Register provides extensive population-based data on all patients who were surgically treated in Sweden since 1990. The authors have analyzed complication data for therapeutic epilepsy surgery procedures performed between 1996 and 2010. Complications are classified as major (affecting daily life and lasting longer than 3 months) or minor (resolving within 3 months).
\end{abstract}

RESULTS A total of 865 therapeutic epilepsy surgery procedures were performed between 1996 and 2010, of which 158 were reoperations. There were no postoperative deaths. Major complications occurred in 26 procedures (3\%), and minor complications in $65(7.5 \%)$. In temporal lobe resections $(n=523)$, there were 15 major $(2.9 \%)$ and 41 minor complications (7.8\%); in extratemporal resections $(n=275)$ there were 9 major $(3.3 \%)$ and 22 minor complications $(8 \%)$; and in nonresective procedures $(n=67)$ there were 2 major $(3 \%)$ and 2 minor complications $(3 \%)$. The risk for any complication increased significantly with age (OR 1.26 per 10 -year interval, $95 \% \mathrm{Cl} 1.09-1.45)$. Compared with previously published results from the same register, there is a trend toward lower complication rates, especially in patients older than 50 years.

CONCLUSIONS This is the largest reported prospective series of complication data in epilepsy surgery. The complication rates comply well with published results from larger single centers, confirming that epilepsy surgery performed in the 6 Swedish centers is safe. Patient age should be taken into account when counseling patients before surgery.

http://thejns.org/doi/abs/10.3171/2014.9.JNS132679

KEY WORDS epilepsy; epilepsy surgery; neurosurgery; adverse effects; multicenter study

$\mathrm{D}$ ESPITE the progress made in the pharmacological treatment of epilepsy over the last half century, up to one-third of all epilepsy patients remain refractory to medical treatment. ${ }^{35}$ However, for some of these patients, epilepsy surgery is an efficacious alternative, which for carefully selected individuals is able to provide freedom from seizures. ${ }^{10,11,35,38}$ As in any surgical procedure, especially elective ones, detailed knowledge of surgical risks is a prerequisite for adequate presurgical counseling. In fact, the perception of risk may be one of the major factors influencing the patient's decision to undergo epilepsy surgery. ${ }^{12}$ To make an informed decision about accepting such an irrevocable treatment option, the patients (and for children, the parents) need to know the potential risks and, if possible, the relevant risk factors. Older age at surgery has been shown in some studies to carry a higher risk for complications, ${ }^{14,32}$ and in 1 study there was a trend toward a higher risk for women. ${ }^{22} \mathrm{It}$ is conceivable that prior neurosurgery including invasive monitoring procedures could lead to more complications, e.g., due to adhesions. Finally, the recording and analysis of complication data are essential for the process of ensuring surgical quality. The publication of complication frequencies will, along with outcome data, enable comparisons between different surgical procedures and different epilepsy surgery centers.

ABBREVIATIONS AH = amygdalohippocampectomy; SNESUR = Swedish National Epilepsy Surgery Register; TLR = temporal lobe resection.

SUBMITTED December 5, 2013. ACCEPTED September 23, 2014.

INCLUDE WHEN CITING Published online October 31, 2014; DOI: 10.3171/2014.9.JNS132679.

DISCLOSURE This study was funded by grants from the Swedish Research Council (Grant No. 521-2011-169) and the Sahlgrenska Academy at Gothenburg University through the LUA/ALF agreement (Grant No. ALFGBG137431). 
Many observational studies on epilepsy surgery outcome include complication data. Despite this, there is a lack of large series that specifically address complications in a methodologically clear and prospective fashion. Recent reviews of complications in epilepsy surgery point out that the differences in definitions and data collection may influence the marked variations in published complication rates. ${ }^{13,15}$ The aim of the present study was to analyze data from the prospective, population-based Swedish National Epilepsy Surgery Register (SNESUR) accrued between 1996 and 2010 regarding major and minor complications, and to search for possible risk factors for complications.

\section{Methods}

Every epilepsy surgery procedure in Sweden is reported to the SNESUR from a defined start of the assessment. This database was initiated by the Swedish Board of Health and Welfare as a quality control register and is controlled by the Swedish Data Inspection Board. All patients whose data are included in the SNESUR have given their informed consent. The Regional Board of Medical Ethics at the University of Gothenburg considered this study to be a quality control study not necessitating further informed consent for research. The register protocol includes data on the patients' social situation, epilepsy history, preoperative seizure situation, and preoperative antiepileptic medication. Coexisting neurological deficits or impairments are also reported. Further items include investigational findings, side and site of the operation, histopathological diagnoses, complications during the presurgical evaluation or at surgery, and a 2-year follow-up of seizure outcome, antiepileptic medication, and psychosocial data. Due to an agreement among the operating centers, register data are analyzed only on a national basis, since the number of patients treated at each institution is limited and the patient selection may vary among centers. However, each center is able to compare its own results to the national reports.

All complications related to epilepsy surgery are reported to SNESUR by the surgical team. Complications are specifically addressed in the register at the time of surgery and at follow-up 3 months after surgery. A complication is defined as an unwanted, unexpected, and uncommon event after a diagnostic or therapeutic procedure. Hence, neither an expected worsening of a hemiparesis after a hemispherectomy nor an upper quadrantanopia after a temporal lobe resection (TLR) is regarded as a complication. Adverse events related to surgery include surgical complications such as intracranial hematomas, deep vein thromboses, and infections as well as neurological complications-meaning any unexpected postoperative neurological impairment. ${ }^{1,32}$ Entirely anesthesiological complications that do not affect neurological function, such as electrolyte imbalance or airway problems, are not included. The severity of a complication is graded as minor if it resolves within 3 months, and major if it lasts longer than 3 months and affects the activities of daily living. Significant neurological deficits are also defined as major, even if activities of daily living are not affected. ${ }^{32}$

The validity of the data collected from the centers is regularly checked by several systems. Intrinsic check- points within the database reject certain impossible combinations. An external revision is regularly performed. Two epilepsy nurses visit all centers and compare the data entered into the database with the original data from the patient files for a random yearly sample of the patients treated at each center. The items controlled in this external revision include side and site of operation, complications, main histopathological findings, and seizure outcome at the 2-year follow-up. So far, there have been no mismatches in the reporting on any of these central items.

The present study includes therapeutic epilepsy surgery procedures performed between January 1996 and December 2010. Complications related to the diagnostic invasive procedures performed during the same period have been reported separately. ${ }^{16}$

Descriptive statistics have been used to report the total complication rates as well as the complication rates according to type of surgery, primary procedures versus reoperations, sex, and a selection of patient age intervals. Univariate binary logistic regression was used to determine the influence of the different variables on major complications as well as on any complication. Odds ratios with corresponding $95 \%$ confidence intervals were calculated. The chi-square and Fisher exact tests were used to explore the relationship between 2 categorical variables. Two-tailed $\mathrm{p}$ values were calculated and values less than 0.05 were considered significant. IBM SPSS version 19 software was used for all statistical analyses.

\section{Results}

During the inclusion period, 865 therapeutic epilepsy surgery procedures were performed. Of these, 158 were reoperations. Patient age at operation ranged from 2 months to 69 years (median 24 years), and 444 patients were male and 421 were female.

There was no surgery-related mortality in this series. One patient who was 20 years old was lost to follow-up due to sudden death 2 months after surgery. In total, major complications occurred in 26 cases (3\%), and there were minor complications in 65 cases $(7.5 \%)$ (Table 1). In primary surgical procedures $(n=707$; patient age at operation 2 months-69 years, median 24 years), major complications occurred in 20 cases $(2.8 \%)$ and minor complications in 54 cases $(7.6 \%)$. In reoperations $(n=158$; patient age at operation 1-56 years, median 23 years), major complications occurred in 6 cases $(3.8 \%)$ and minor complications in 11 cases (7\%). There was a slight, nonsignificant difference in the rate of major complications between male (2.7\% major [12 of 444 ], $7.4 \%$ minor [33 of 444]) and female patients (3.3\% major [14 of 421], $7.6 \%$ minor [32 of 421]).

In TLRs $(\mathrm{n}=523)$, there were 15 major $(2.9 \%)$ and 41 minor complications (7.8\%) (Table 2). Complications were more common in patients who had resections that included hippocampus (11.1\% [ $\mathrm{n}=37$ of 332]; 9 major and 28 minor) than when the resections excluded hippocampus (7.1\% [n $=12$ of 169]; 4 major and 8 minor). However, the difference was not statistically significant $(p=0.202)$. In the small group of patients who underwent selective amygdalohippocampectomy $(\mathrm{AH})(\mathrm{n}=22)$, there was a 
TABLE 1. Complications after 865 surgical procedures

\begin{tabular}{lcc}
\hline \multicolumn{1}{c}{ Type of Complication } & $\begin{array}{c}\text { Major } \\
\text { Complications (\%) }\end{array}$ & $\begin{array}{c}\text { Minor } \\
\text { Complications (\%) }\end{array}$ \\
\hline Surgical complications & & \\
\hline Infection & $1(<0.1)$ & $18(2.1)$ \\
\hline Hematoma & $2(0.2)$ & $12(1.4)$ \\
\hline DVT/pulmonary embolism & 0 & $5(0.6)$ \\
\hline Hydrocephalus & 0 & $2(0.2)$ \\
\hline CSF leakage & 0 & $4(0.5)$ \\
\hline Brain edema & 0 & $1(<0.1)$ \\
\hline Neurological complications & & $11(1.3)$ \\
\hline Hemi/monoparesis & $12(1.4)$ & $2(0.2)$ \\
\hline Sensory deficit & $1(<0.1)$ & $1(<0.1)^{\star}$ \\
\hline Hemianopia & $6(0.7)$ & $8(0.9)$ \\
\hline Cranial nerve effects & $4(0.5)$ & $9(1.0)$ \\
\hline Dysphasia & $2(0.2)$ & 0 \\
\hline Other & $3(0.3) \dagger$ & $65(7.5) \S$ \\
\hline Total & $26(3.0) \ddagger$ &
\end{tabular}

DVT = deep venous thrombosis.

* Transient hemianopia in a patient undergoing parietal lobe resection. $\dagger$ This includes 1 patient with thalamic infarction due to perforating artery injury, 1 patient with air embolism, and 1 patient with permanent postoperative anosmia.

$\ddagger$ One patient had both a hemiparesis and a cranial nerve paresis, 1 patient a cerebral abscess and a persistent hemiparesis, 1 patient a postoperative hematoma and a persistent hemiparesis, 1 patient a persistent hemianopia and a persistent sensory deficit, and 1 patient a postoperative hematoma and a persistent hemianopia. These patients are counted only once in the sum row. $\S$ One patient had a transient dysphasia and a sensory deficit, 2 patients a postoperative hematoma with a transient hemiparesis, 1 patient a hematoma and subsequent hydrocephalus, 1 patient had a meningitis and CSF leakage, 1 patient an infection and a postoperative hematoma, 1 patient a transient hemiparesis and dysphasia, and 1 a hematoma with transient dysphasia. These patients are counted only once in the sum row.

high total rate of complications (7 of 22, 31.8\%; 2 major and 5 minor) compared with the other groups of patients with TLRs (49 of 501, 9.8\%, 13 major and 36 minor; $\mathrm{p}$ $=0.005)$. In extratemporal resections $(\mathrm{n}=275), 9$ major (3.3\%) and 22 minor complications (8\%) occurred, and in nonresective procedures $(\mathrm{n}=67)$ there were 2 major $(3 \%)$ and 2 minor complications (3\%).

The complications in children (age 2 months-18 years, median 11 years) according to the type and location of the surgical procedure are specified in Table 3 . In total, there were 8 major (2.4\%) and 14 minor complications (4.3\%) in pediatric patients. In the subset of patients up to 3 years of age ( $\mathrm{n}=38$; age $2-35$ months, median 16 months), 1 major $(2.6 \%)$ and 1 minor complication (2.6\%) occurred. The procedures performed in this subgroup comprised 17 hemispherectomies, 8 frontal lobe resections, 5 TLRs, 3 multilobar resections, 2 callosotomies, 2 parietal lobe resections, and 1 occipital resection. Six of the procedures were reoperations.

The complications in adults (age 18-69 years, median 34 years) according to the type and location of the surgical procedure are listed in Table 3 . In the subset of patients 35 years or older at the time of surgery $(n=257$, median 43 years), 11 major (4.3\%) and 31 minor compli- cations $(12.1 \%)$ occurred. In patients 50 years or older (n $=64)$, there were no major complications and 7 minor complications (10.9\%) (Fig. 1).

In the binary logistic regression, the risk for any complication was found to increase significantly with age (OR 1.26 per 10 year-interval, 95\% CI 1.09-1.45). Similarly, the risk was increased for adults (OR 2.05, 95\% CI 1.243.39 ) and for patients 35 years or older (OR 2.23, 95\% CI 1.43-3.46). For major complications only, the relationship was not significant (OR 1.14 per 10 year-interval, 95\% CI $0.886-1.46)$. Sex, reoperation, type of surgery, and previous invasive investigations were not significant factors in either group.

A previously published series from SNESUR reported the complications in the years $1990-1995 .^{32}$ To look for temporal trends, the whole period 1990-2010 was divided into four 5 -year periods. There were no significant differences in complication rates between these groups. When the entire series 1996-2010 was compared with 1990-1995, the total complication rate was lower for any surgical procedure (10.5\% vs $12 \%)$ as well as for temporal resections (10.7\% vs $12.1 \%$ ), for extratemporal resections $(11.3 \%$ vs $14.8 \%)$, and for nonresective procedures $(6 \%$ vs $8.2 \%$ ), although these differences are not statistically significant. In the earlier cohort, there was a high rate of major complications in patients older than 50 years ( 3 of $22,13.6 \%)^{32}$ Because there were no major complications in this subgroup in the present series, the difference is significant $(p=0.015)$. The total rate of complications $(7$ of 64 [10.9\%] vs 4 of 22 [18.2\%]) did not differ significantly between the cohorts.

\section{Discussion}

In this study we found an overall rate of 3\% major and $7.5 \%$ minor complications in epilepsy surgery. For TLRs, the most common procedure in epilepsy surgery, we found an overall rate of $2.9 \%$ major and $7.8 \%$ minor complications.

In studies with prospective data collection and a similar subdivision of complications into major and minor (or permanent and transient), major complications are reported in 3\%-10.6\% and minor complications in $7.4 \%-$ $10.7 \% .^{1,17}$ For TLRs, the corresponding figures are $0 \%-$ $10.9 \%$ for major complications and $5.5 \%-10.9 \%$ for minor complications. . $^{1,517,25}$ In a randomized controlled study of TLRs, there were $10 \%$ with adverse effects of surgery. In this study, complications were not divided into major and minor. ${ }^{38}$ In retrospective studies and in those in which the method for data collection is not stated, complication rates are presented in the range of $0 \%-7.5 \%$ major and $5.6 \%-$ $15.2 \%$ minor complications for any procedure, $, 8,9,23,28,31,36$ and for TLRs there were $0 \%-7 \%$ major complications and $0 \%-21.8 \%$ minor complications. ${ }^{5,6,18,19,23,26,29,30,34,36,37}$ In pediatric cohorts, $0 \%-14.6 \%$ major and $5.2 \%-19 \%$ minor complications are presented for various kinds of procedures. $3,4,7,20,33$ In a systematic review of 76 studies in which different methodologies were used, Hader et al. found $1.5 \%$ major and $5.1 \%$ minor medical complications and $4.7 \%$ major and $10.9 \%$ minor neurological complications..$^{15}$ 
TABLE 2. Complications after 523 TLRs in relation to type of surgery

\begin{tabular}{|c|c|c|c|c|c|c|c|c|}
\hline \multirow[b]{2}{*}{ Type of Complication } & \multicolumn{2}{|c|}{$\begin{array}{l}\text { No. }(\%) \text { w/ TLR Excluding } \\
\text { Hippocampus; } n=169\end{array}$} & \multicolumn{2}{|c|}{$\begin{array}{l}\text { No. }(\%) \text { w/ TLR Including } \\
\text { Hippocampus; } n=332\end{array}$} & \multicolumn{2}{|c|}{$\begin{array}{c}\text { No. (\%) w/ Selective AH; } \\
n=22\end{array}$} & \multicolumn{2}{|c|}{ Total (\%); $n=523$} \\
\hline & Major & Minor & Major & Minor & Major & Minor & Major & Minor \\
\hline \multicolumn{9}{|l|}{ Surgical complications } \\
\hline Infection & & $1(0.6)$ & & $8(2.4)^{*}$ & & $1(4.5)$ & & $10(1.9)$ \\
\hline Hematoma & $1(0.6) \dagger$ & $2(1.2) \ddagger$ & & $5(1.5)^{*}$ & & $1(4.5) \S$ & $1(0.2)$ & $8(1.5)$ \\
\hline DVT/pulmonary embolism & & $2(1.2)$ & & $3(0.9)$ & & & & $5(1.0)$ \\
\hline Hydrocephalus & & & & $1(0.3)^{\star}$ & & & & $1(0.2)$ \\
\hline CSF leakage & & & & $3(0.9)$ & & & & $3(0.6)$ \\
\hline Brain edema & & & & $1(0.3)$ & & & & $1(0.2)$ \\
\hline \multicolumn{9}{|l|}{ Neurological complications } \\
\hline Hemi/monoparesis & $1(0.6)$ & & $2(0.6)$ & $2(0.6)$ & $2(9.1)$ & $2(9.1) \S$ & $5(1.0)$ & $4(0.8)$ \\
\hline Sensory deficit & & & $1(0.3) \rrbracket$ & $1(0.3)^{*}$ & & & $1(0.2)$ & $1(0.2)$ \\
\hline Hemianopia & $1(0.6) \dagger$ & & $4(1.2) \Uparrow$ & & & & $5(1.0)$ & \\
\hline Cranial nerve effects & $1(0.6)$ & $1(0.6)$ & $2(0.6)$ & $3(0.9)$ & & $2(9.1)$ & $3(0.6)$ & $6(1.1)$ \\
\hline Dysphasia & $1(0.6)$ & $3(1.8) \ddagger$ & & $4(1.2)^{*}$ & & & $1(0.2)$ & $7(1.3)$ \\
\hline Other & & & $1(0.3)^{\star *}$ & & & & $1(0.2)$ & \\
\hline Total & $4(2.4)$ & $8(4.7)$ & $9(2.7)$ & $28(8.4)$ & $2(9.1)$ & $5(22.7)$ & $15(2.9)$ & $41(7.8)$ \\
\hline
\end{tabular}

* One patient had an infection and a hematoma; 1 had dysphasia and a sensory deficit; and 1 had a hematoma and subsequent hydrocephalus (patients are counted only once in the sum row, even if they suffered $>1$ complication).

$\dagger$ One patient had a hematoma and persistent hemianopia.

$\ddagger$ One patient had a hematoma and transient dysphasia.

$\S$ One patient had a hematoma and transient hemiparesis.

I One patient had a persistent hemianopia and sensory deficit.

** This patient had a thalamic infarction due to perforating artery injury.

In the aforementioned reports, direct comparisons are difficult, not only because of differences in the range of surgical procedures, in characteristics of the patient cohorts, and in methods of data collection, but also because different definitions of surgical complications were used or not stated. For instance, some studies used the limit of 1 year for permanent morbidity instead of the 3-months limit used in our study. ${ }^{1,36}$ Several studies explicitly included expected deficits or did not state whether postoperative deficits were judged to be expected, thus potentially yielding significantly higher complication rates. ${ }^{3,7,21,34}$ Another important difference is the study design. It is notable that, with a single exception, studies with remarkably low complication frequencies had a retrospective design, which increases the risk for collection bias. ${ }^{6,24,30,36}$ One prospective study (of TLRs in children) was unique in presenting no major complications; however, in this study the total rate of complications $(5.5 \%)$ was similar to the total rate in the present study $(5.2 \%) .{ }^{25}$

In an earlier study from SNESUR, 3.1\% major and $8.9 \%$ minor complications were reported. ${ }^{32}$ Because the same register was used for the analysis as in the present study (although before 1995 the register had both retrospectively and prospectively collected data), comparisons are possible. In the present series the complication rates are lower, but the difference is not statistically significant. Because there has been a generation shift among epilepsy surgeons in several Swedish centers over the last 2 decades, the implication of a significant learning curve seems unlikely. We interpret the positive trend observed to indicate improvements in preoperative workup and in surgical technique, most notably the more widespread use of neuronavigation.

In this study, older age was associated with an increased risk for complications. Several previous studies have indicated age as a risk factor for complications in patients undergoing epilepsy surgery. ${ }^{14,32,37}$ However, in 2 studies, no difference could be found in complication frequencies for patients younger or older than 50 years. ${ }^{26,31}$ Although older age was a risk factor for complications in this study, we found no cutoff above which the risk for complications is unacceptably high. (There were actually no major complications among patients older than 50 years.) It is also important to recognize that age does not preclude favorable seizure outcome in epilepsy surgery. ${ }^{2,8,14,31}$ Therefore, we think older age should be a factor to consider in patient counseling but should not be regarded as a contraindication to surgery. Compared with the cohort treated between 1990 and 1995, there was a significant reduction in major complications in patients older than 50 years. Because of the small number of patients, this result should be interpreted cautiously. The total rate of major complications in elderly patients in the course of 20 years does not differ significantly from the younger adult population. ${ }^{2}$ If there is a real reduction of complications in the elderly patients, it may imply improvements in patient selection.

In TLRs, it is known that more extensive resections may increase the risk for complications, especially visual field defects. ${ }^{27,39}$ In this study we confirm this; we found a nonsignificant trend toward complications being more common when the resections include hippocampus. Se- 
TABLE 3. Complication rates for different surgical procedures in children and adults

\begin{tabular}{|c|c|c|c|}
\hline Surgical Procedure & No. of Patients & Major Complications (\%) & Minor Complications (\%) \\
\hline \multicolumn{4}{|l|}{ Pediatric patients } \\
\hline Temporal lobe resection & 122 & $3(2.5)$ & $2(1.6)$ \\
\hline Frontal lobe resection & 69 & $3(4.3)$ & $3(4.3)$ \\
\hline Parietal lobe resection & 28 & $1(3.6)$ & $3(10.7)$ \\
\hline Occipital lobe resection & 10 & 0 & 0 \\
\hline Multilobar resection & 11 & 0 & $1(9.1)$ \\
\hline Hemispherectomy & 40 & 0 & $3(7.5)$ \\
\hline Callosotomy & 24 & $1(4.2)$ & 0 \\
\hline Hamartoma disconnection & 11 & 0 & $1(9.1)$ \\
\hline Multiple subpial transection only & 10 & 0 & $1(10)$ \\
\hline Stereotactic lesion & 1 & 0 & 0 \\
\hline Exploration only & 1 & 0 & 0 \\
\hline Other & 1 & 0 & 0 \\
\hline Total children & 328 & $8(2.4)$ & $14(4.3)$ \\
\hline \multicolumn{4}{|l|}{ Adult patients } \\
\hline Temporal lobe resection & 401 & $12(3.0)$ & $39(9.7)$ \\
\hline Frontal lobe resection & 73 & $1(1.4)$ & $7(9.6)$ \\
\hline Parietal lobe resection & 16 & $2(12.5)$ & $2(12.5)$ \\
\hline Occipital lobe resection & 17 & $1(5.9)$ & $1(5.9)$ \\
\hline Multilobar resection & 8 & $1(12.5)$ & $1(12.5)$ \\
\hline Hemispherectomy & 3 & 0 & $1(33.3)$ \\
\hline Callosotomy & 7 & 0 & 0 \\
\hline Hamartoma disconnection & 4 & $1(25.0)$ & 0 \\
\hline Multiple subpial transection only & 4 & 0 & 0 \\
\hline Stereotactic lesion & 2 & 0 & 0 \\
\hline Exploration only & 1 & 0 & 0 \\
\hline Other & 1 & 0 & 0 \\
\hline Total adults & 537 & $18(3.4)$ & $51(9.5)$ \\
\hline
\end{tabular}

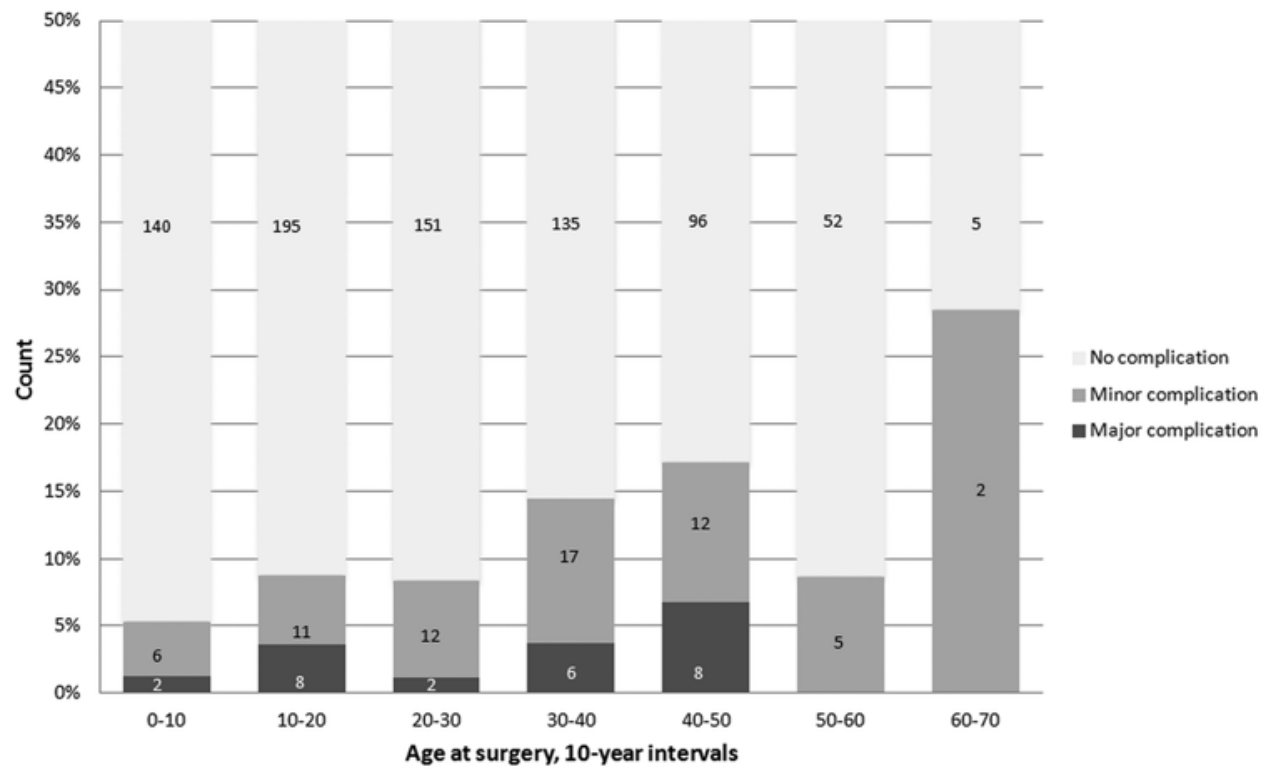

FIG. 1. Bar graph showing number of patients and complication frequencies in relation to age (in years) at surgery. 
lective AHs comprised only $4 \%$ of the TLRs in the present series. In this small group there was a very high rate of complications, which illustrates the importance of surgical experience in this type of surgery.

In a previously published report, complications related to invasive electrode workup significantly increased the risk for complications related to therapeutic resections. ${ }^{16}$ In this study, previous invasive workup as a whole was not identified as a risk factor for complications during therapeutic surgery. Because invasive workup with grid electrodes is often performed in close temporal relationship to a subsequent resection, there presumably is some form of interaction between complications in the 2 types of procedures. One possibility is that the brain is more vulnerable after 1 or 2 weeks with grid electrode monitoring. The exact nature of the relationship is unknown and needs to be investigated in larger, prospective studies of invasive electrode procedures.

The major strengths of the present study are the very large number of patients and the completely prospective nature of the data collection. In fact, to our knowledge, this study represents the largest reported prospective series of complication data in epilepsy surgery. Most previously published complication studies are single-center series. Since all Swedish epilepsy surgery centers use the same register with a very low frequency of patients lost to follow-up (only 1 of 865 procedures in this study), SNESUR provides population-based data. The factors stated above support the internal and external validity of the present study.

One limitation of the study is that complications are specifically addressed only during the postoperative inhospital stay and at follow-up 3 months after surgery. Very late surgical complications such as hydrocephalus developing several months after surgery are therefore not included. Furthermore, due to insufficient data, no analysis could be made of the impact of medical comorbidities for complications in epilepsy surgery.

\section{Conclusions}

The present study is the largest reported prospective series of complication results in epilepsy surgery. In combination with the population-based nature of the data, this supports its validity as a basis for patient information and quality control in epilepsy surgery. Although direct comparisons are not feasible, the complication rates in this study conform well with series with similar methodology from other centers, confirming that epilepsy surgery performed in the 6 Swedish centers is safe. Compared with previously published results from the same register, there is a trend toward lower complication rates, which may indicate improvements in surgical quality. Older age at operation was confirmed to be associated with a slightly higher risk for complications and should be taken into account when counseling patients.

\section{Acknowledgments}

We thank Mattias Molin and Anna Edelvik for statistical assistance, Gerd Ekstedt for help with the data collection, the steering committee of the SNESUR, and all of the Swedish epilepsy sur- gery teams (in Gothenburg, Linköping, Lund, Stockholm, Umeå, and Uppsala).

\section{References}

1. Behrens E, Schramm J, Zentner J, König R: Surgical and neurological complications in a series of 708 epilepsy surgery procedures. Neurosurgery 41:1-10, 1997

2. Bialek F, Rydenhag B, Flink R, Malmgren K: Outcomes after epilepsy surgery in patients over 50 years of age in Sweden 1990-2009 - a prospective longitudinal study. Seizure 23: 641-645, 2014

3. Bourgeois M, Sainte-Rose C, Lellouch-Tubiana A, Malucci C, Brunelle F, Maixner W, et al: Surgery of epilepsy associated with focal lesions in childhood. J Neurosurg 90:833-842, 1999

4. Clusmann H, Kral T, Gleissner U, Sassen R, Urbach H, Blümcke I, et al: Analysis of different types of resection for pediatric patients with temporal lobe epilepsy. Neurosurgery $\mathbf{5 4 : 8 4 7 - 8 6 0 , 2 0 0 4}$

5. Clusmann H, Schramm J, Kral T, Helmstaedter C, Ostertun B, Fimmers R, et al: Prognostic factors and outcome after different types of resection for temporal lobe epilepsy. $\mathbf{J}$ Neurosurg 97:1131-1141, 2002

6. Cohen-Gadol AA, Wilhelmi BG, Collignon F, White JB, Britton JW, Cambier DM, et al: Long-term outcome of epilepsy surgery among 399 patients with nonlesional seizure foci including mesial temporal lobe sclerosis. J Neurosurg 104:513-524, 2006

7. Cossu M, Lo Russo G, Francione S, Mai R, Nobili L, Sartori I, et al: Epilepsy surgery in children: results and predictors of outcome on seizures. Epilepsia 49:65-72, 2008

8. Costello DJ, Shields DC, Cash SS, Eskandar EN, Cosgrove GR, Cole AJ: Consideration of epilepsy surgery in adults should be independent of age. Clin Neurol Neurosurg 111:240-245, 2009

9. Donadío M, D'Giano C, Moussalli M, Barrios L, Ugarnes G, Segalovich M, et al: Epilepsy surgery in Argentina: long-term results in a comprehensive epilepsy centre. Seizure 20:442445, 2011

10. Engel J Jr, McDermott MP, Wiebe S, Langfitt JT, Stern JM, Dewar S, et al: Early surgical therapy for drug-resistant temporal lobe epilepsy: a randomized trial. JAMA 307:922-930, 2012

11. Engel J Jr, Wiebe S, French J, Sperling M, Williamson P, Spencer D, et al: Practice parameter: temporal lobe and localized neocortical resections for epilepsy: report of the Quality Standards Subcommittee of the American Academy of Neurology, in association with the American Epilepsy Society and the American Association of Neurological Surgeons. Neurology 60:538-547, 2003

12. Erba G, Messina P, Pupillo E, Beghi E: Acceptance of epilepsy surgery among adults with epilepsy-what do patients think? Epilepsy Behav 24:352-358, 2012

13. Georgiadis I, Kapsalaki EZ, Fountas KN: Temporal lobe resective surgery for medically intractable epilepsy: a review of complications and side effects. Epilepsy Res Treat 2013:752195, 2013

14. Grivas A, Schramm J, Kral T, von Lehe M, Helmstaedter C, Elger CE, et al: Surgical treatment for refractory temporal lobe epilepsy in the elderly: seizure outcome and neuropsychological sequels compared with a younger cohort. Epilepsia 47:1364-1372, 2006

15. Hader WJ, Tellez-Zenteno J, Metcalfe A, Hernandez-Ronquillo L, Wiebe S, Kwon CS, et al: Complications of epilepsy surgery: a systematic review of focal surgical resections and invasive EEG monitoring. Epilepsia 54:840-847, 2013

16. Hedegärd E, Bjellvi J, Edelvik A, Rydenhag B, Flink R, Malmgren K: Complications to invasive epilepsy surgery 
workup with subdural and depth electrodes: a prospective population-based observational study. J Neurol Neurosurg Psychiatry 85:716-720, 2014

17. Heller AC, Padilla RV, Mamelak AN: Complications of epilepsy surgery in the first 8 years after neurosurgical training. Surg Neurol 71:631-637, 2009

18. Ipekdal HI, Karadas O, Erdogan E, Gokcil Z: Spectrum of surgical complications of temporal lobe epilepsy surgery: a single-center study. Turk Neurosurg 21:147-151, 2011

19. Jutila L, Immonen A, Mervaala E, Partanen J, Partanen K, Puranen M, et al: Long term outcome of temporal lobe epilepsy surgery: analyses of 140 consecutive patients. J Neurol Neurosurg Psychiatry 73:486-494, 2002

20. Kan P, Van Orman C, Kestle JR: Outcomes after surgery for focal epilepsy in children. Childs Nerv Syst 24:587-591, 2008

21. Kim SK, Wang KC, Hwang YS, Kim KJ, Chae JH, Kim IO, et al: Epilepsy surgery in children: outcomes and complications. J Neurosurg Pediatr 1:277-283, 2008

22. Koubeissi MZ, Puwanant A, Jehi L, Alshekhlee A: In-hospital complications of epilepsy surgery: a six-year nationwide experience. Br J Neurosurg 23:524-529, 2009

23. Lee JH, Hwang YS, Shin JJ, Kim TH, Shin HS, Park SK: Surgical complications of epilepsy surgery procedures: experience of 179 procedures in a single institute. J Korean Neurosurg Soc 44:234-239, 2008

24. McClelland S III, Guo H, Okuyemi KS: Population-based analysis of morbidity and mortality following surgery for intractable temporal lobe epilepsy in the United States. Arch Neurol 68:725-729, 2011

25. Mittal S, Montes JL, Farmer JP, Rosenblatt B, Dubeau F, Andermann F, et al: Long-term outcome after surgical treatment of temporal lobe epilepsy in children. J Neurosurg 103 (5 Suppl):401-412, 2005

26. Murphy M, Smith PD, Wood M, Bowden S, O’Brien TJ, Bulluss KJ, et al: Surgery for temporal lobe epilepsy associated with mesial temporal sclerosis in the older patient: a longterm follow-up. Epilepsia 51:1024-1029, 2010

27. Nilsson D, Malmgren K, Rydenhag B, Frisén L: Visual field defects after temporal lobectomy - comparing methods and analysing resection size. Acta Neurol Scand 110:301-307, 2004

28. Ozkara C, Ozyurt E, Hanoglu L, Eskazan E, Dervent A, Koçer N, et al: Surgical outcome of epilepsy patients evaluated with a noninvasive protocol. Epilepsia 41 (Suppl 4):S41S44, 2000

29. Ozkara C, Uzan M, Benbir G, Yeni N, Oz B, Hanoğlu L, et al: Surgical outcome of patients with mesial temporal lobe epilepsy related to hippocampal sclerosis. Epilepsia 49:696699, 2008

30. Paglioli E, Palmini A, Paglioli E, da Costa JC, Portuguez M, Martinez JV, et al: Survival analysis of the surgical outcome of temporal lobe epilepsy due to hippocampal sclerosis. Epilepsia 45:1383-1391, 2004
31. Patra S, Elisevich K, Podell K, Schultz L, Gaddam S, Smith $\mathrm{B}$, et al: Influence of age and location of ictal onset on postoperative outcome in patients with localization-related epilepsy. Br J Neurosurg 28:61-67, 2014

32. Rydenhag B, Silander HC: Complications of epilepsy surgery after 654 procedures in Sweden, September 1990-1995: a multicenter study based on the Swedish National Epilepsy Surgery Register. Neurosurgery 49:51-57, 2001

33. Sinclair DB, Aronyk K, Snyder T, McKean J, Wheatley M, Bhargava R, et al: Pediatric temporal lobectomy for epilepsy. Pediatr Neurosurg 38:195-205, 2003

34. Sindou M, Guenot M, Isnard J, Ryvlin P, Fischer C, Mauguière $\mathrm{F}$ : Temporo-mesial epilepsy surgery: outcome and complications in 100 consecutive adult patients. Acta Neurochir (Wien) 148:39-45, 2006

35. Spencer S, Huh L: Outcomes of epilepsy surgery in adults and children. Lancet Neurol 7:525-537, 2008

36. Tanriverdi T, Ajlan A, Poulin N, Olivier A: Morbidity in epilepsy surgery: an experience based on 2449 epilepsy surgery procedures from a single institution. Clinical article. J Neurosurg 110:1111-1123, 2009

37. Vale FL, Reintjes S, Garcia HG: Complications after mesial temporal lobe surgery via inferiortemporal gyrus approach. Neurosurg Focus 34(6):E2, 2013

38. Wiebe S, Blume WT, Girvin JP, Eliasziw M: A randomized, controlled trial of surgery for temporal-lobe epilepsy. N Engl J Med 345:311-318, 2001

39. Winston GP: Epilepsy surgery, vision, and driving: what has surgery taught us and could modern imaging reduce the risk of visual deficits? Epilepsia 54:1877-1888, 2013

\section{Author Contributions}

Conception and design: Malmgren. Acquisition of data: Flink, Rydenhag. Analysis and interpretation of data: Malmgren, Bjellvi, Rydenhag. Drafting the article: Bjellvi. Critically revising the article: Malmgren. Reviewed submitted version of manuscript: all authors. Approved the final version of the manuscript on behalf of all authors: Malmgren. Statistical analysis: Bjellvi. Study supervision: Malmgren.

\section{Supplemental Information \\ Previous Presentation}

Portions of this work were presented in abstract and poster form at the 10th European Congress on Epileptology held in London, England, in 2012 (Bjellvi et al. Epilepsia 2012;53[Suppl 5]:181).

\section{Correspondence}

Kristina Malmgren, Epilepsy Research Group, Institute of Neuroscience and Physiology, Department of Clinical Neuroscience and Rehabilitation, Per Dubbsgatan 141 tr, Sahlgrenska Academy at University of Gothenburg, 41345 Göteborg, Sweden. email: kristina.malmgren@neuro.gu.se. 